Saudi Journal of Oral and Dental Research

Abbreviated Key Title: Saudi J Oral Dent Res

ISSN 2518-1300 (Print) |ISSN 2518-1297 (Online)

Scholars Middle East Publishers, Dubai, United Arab Emirates

Journal homepage: https://saudijournals.com/sjodr

Review Article

\title{
Impressions in Dental Implants: A Review
}

Dr. Yogesh Santoba Nagargoje ${ }^{1 *}$, Dr. Garima Sharma ${ }^{2}$, Dr. Siddharth Narula ${ }^{3}$, Dr. Girish Kumar ${ }^{4}$, Dr. Deepak Mahla ${ }^{5}$, Dr. Namrata Mahajan ${ }^{6}$

${ }^{1,2}$ Post-Graduation student, ${ }^{3}$ Professor \& HOD, ${ }^{4,5}$ Associate Professor, ${ }^{6}$ Assistant Professor, Department of Prosthodontics Crown Bridges and Implantalogy, Rajasthan Dental College and Hospital, Jaipur, Rajathan India

DOI: $\underline{10.36348 / \text { sjodr.2020.v05i09.011 }}$

| Received: 04.09.2020 | Accepted: 14.09.2020 | Published: 19.09.2020

*Corresponding author: Dr. Yogesh Santoba Nagargoje

Abstract

Replacement of missing tooth with dental implants is the alternative success treatment in present days. There are many options and varieties of materials present for implant treatment .For the success of the dental implants impression making is also an important factor. Errors in impression making impression making mainly leads to improper placement of the prosthesis and leads to implant failure so selection technique of impression for that particular clinical situation is always important for dental implant success. The main aim of this review article is how to select an impression technique for particular clinical situation.

Keywords: Impressions, Dental Implants.

Copyright @ 2020: This is an open-access article distributed under the terms of the Creative Commons Attribution license which permits unrestricted use, distribution, and reproduction in any medium for non-commercial use (NonCommercial, or CC-BY-NC) provided the original author and source are credited.

\section{INTRODUCTION}

The use of dental implants to replace the natural tooth has become a common practice in the contemporary restorative and surgical dentistry. In modern dentistry dental implant play most vital role in the replacement of missing teeth. Implants provide excellent support for fixed as well as removable prosthesis, which increases function, compared with conventional complete and partial denture prosthesis and restores esthetics of the patients. Prosthodontic rehabilitation with osseointegrated implant turned out to be the therapeutic solution of choice for treating partially or completely edentulous arches .Implant impression is one of the most important steps in achieving passive fit by accurately relating an analogue of the implant or implant abutment to the other structures in the dental arch. Further the accuracy of impression is affected by the selection of impression tray, impression technique and type of impression material, number and angulation of implant [1-3].

\section{IMPLANT COMPONENTS}

The success, function and aesthetics of an implant restoration are dependent on the proper treatment planning and through knowledge of components and instrumentation commonly used components are drivers, healing abutments, lab analogues, screws and impression coping's.

\section{Drivers}

Drivers are designed to carry different types of components of implant to the mouth for easier placement and removal. The driver head design can be square, hexagonal and abutment driver and contra-angle torque driver.

\section{Healing abutments}

Based on clinical situation healing abutments available in various lengths and diameters

\section{Laboratory analogues}

Laboratory analogues are metal replicas that duplicate the implant head or abutment connected to the implant which are used in laboratory to construct working model.

\section{Impression copings}

Impression copings have been used in making final impressions when soft tissue matures completely around the healing abutment. These copings have the same flare as the healing abutments and should fully support the soft tissue around the head of the implant .They are various types of copings available which are selected based on the impression techniques. In transfer type the coping is retained in the mouth when set impression is removed. In pick up type the coping gets incorporated in the impression and it is removed from the mouth with the set impression. 


\section{Abutments}

Abutments are components that substitute for missing coronal structure that attach directly to the head of the implant and extend through the gingival into the oral cavity.

\section{Considerations for abutment selection}

Position and angulation of the implant, height and thickness of the surrounding soft tissue, the interocclusal space and the type of restoration to be placed,the height of the lip line, the occlusal scheme and position of the tooth in the arch.

\section{The abutment types}

Standard abutment, angulated abutments, UCLA abutment (preparable abutments), provisional abutments, titanium abutments, ceramic abutments, prefabricated conical abutments and custom machined abutment [5].

\section{Factors determining the accuracy of impressions}

1. Number of implants: Impression making of multiple implants are complicated than single implant. The positional errors in restorative stage are less likely to affect the passive fit in single implant. Daoydi MF et al found that a positional error in the restorative stage is unlikely to affect the passive fit with the implant. But rotational or dimensional discrepancy in the impression is likely to affect the appearance, contact points and occlusal requirements.

2. Position of implants: The amount of distortion is limited in parallel abutments. In case of non-parallel abutments, the direct transfer method provides the accurate working cast when compared to the indirect method $[6,7]$.

3. Impression material: The appropriate selection of impression material and tray bring the accuracy of the cast. The choice of material varies according to the complexity of work, impression technique, tray, implant system and prosthetic components to be used. Elastomeric impression material seems to be logical, since they prevent impression displacement due to the rigidity. They are stable in diameters, resistant in deformation, have low strain when under pressure, and they also have high initial shear strength. The unpleasant smell and polymerization reactions of poly sulfide make it difficult to use. Condensation silicones are dimensionally less stable. Mostly poly ether and addition cured silicones are used. The amount of expansion of polyether makes the transfer loose and mobile in impression. Therefore not suitable for techniques using impression transfer. Polyether and addition silicone are preferred in presence of undercuts and multiple implants [6].

4. Type of Impression Tray: Selection of a tray is an effective factor on accuracy of impression. Impression trays can be either custom made or stock trays. Generally custom made trays are preferred since it permits a uniform thickness of impression material. It has been determined that applying special hard trays is better than polycarbonate trays because rigid stainless steel trays limit the distortion of the impression $[7,8]$.

5. Design of the coping: Shortened length connection screw eases the removal of the coping from the implant in open tray technique. Roberto Sorrentino et al stated that shortened connection length compensated the higher removal stress in angulated implants. The coping length extended inside the impression material plays an important role in retention and resistance against displacement.New modifications like acrylic resin transfer caps, gold machined castable abutments have been introduced to improve the accuracy of impression.

6. Splinting transfer coping: Inaccuracies in the impression during clinical and lab phase may occur due to the movement of the copings in multiple implants. To obtain maximum accuracy, splinting of transfer copings plays an important role in case of multiple implants.

7. Surface treatment of coping: To enhance the accuracy, the coping can be treated with air-borne particle abrasion and impression adhesive $[10,11]$.

\section{Classification of the implant impressions [12]}

\begin{tabular}{|l|l|l|l|}
\hline \multicolumn{2}{|c|}{ Conventional } & Digital \\
\hline $\begin{array}{l}\text { 1.At the time of surgical placement of the } \\
\text { fixture(bone indexing) }\end{array}$ & 2.After the fixture placement & $\begin{array}{l}\text { Chair side } \\
\text { production }\end{array}$ \\
\cline { 2 - 4 } & Based on level of impresson & Abutment level & $\begin{array}{l}\text { Laboratory } \\
\text { production }\end{array}$ \\
\hline Tray method & Implant level(based on coping) & Abentralised \\
& & & a.Pick up type \\
Jig method & $\begin{array}{l}\text { b.transfer type } \\
\text { c.snap fi }\end{array}$ & & \\
& & & \\
\hline
\end{tabular}


Implant Indexing: [11, 12]

Implant Indexing is a method in which impression is made at the time of surgical placement. This allows for the preparation of an abutment and provisional crown placement for one stage procedure or the provisional crown is inserted instead of healing abutment at the time of exposure in two stage implant procedure. It is of two types: tray technique and jig technique.

Tray technique: Pick-up coping used in this technique recommended minimizing the amount of force loaded onto the newly placed implant using a traditional tray.

Jig technique: Prior to surgery a jig is fabricated to avoid using the impression material while the surgical flap is opened. An acrylic splint including 3-4 adjacent teeth should be fabricated on a diagnostic cast. Space is created in the jig for the future impression coping. After surgical placement of implant fixture, place the pick- up coping. A cold sterilized jig is positioned in the mouth. Relate the coping to the jig using liquid acrylic or Triad gel. Make sure that the coping screw rotates freely and the undercut is not blocked. The acrylic or gel can be cured now. Release the coping screw and free the splint with the abutment in it. Release space in the stone cast to accommodate the implant analog. Position the jig and attached analog. Pour the stone and remove the jig once the stone is set. The implant is indexed onto the model.

\section{After the fixture placement [13, 14]}

A. Pick up impression / open tray/direct method: Open tray technique is better than closed tray technique, especially in case of larger number of implants and in edentulous patients. The open-tray impression technique exhibited higher accuracy in comparison to closed-tray technique with TC and TCCap. The open tray technique reduces the effect of implant angulation, deforming the impression material upon recovery from mouth, and removes the concern of replacing the copings into the impression. Open-tray metal splinted impression coping was significantly superior and was quite more precise. The technique can be further subdivided into splinted and non-splinted techniques. The splinting procedure is recommended in case of multiple implants to decrease the amount of distortion and to improve impression accuracy and implant stability. Splinting of the transfer copings prevents rotational movement of impression copings in the impression material during analog fastening, which provides better results than not splinting. Accuracy of a splinted impression technique depends upon its resistance to deformation under the forces of impression material; hence the use of rigid splint material is essential for accurate master cast
B. Transfer Type / Close Tray Technique/Indirect method: In this technique the impression copings remain in the mouth on the removal of the set impressions. After the removal of the impression, the impression copings are transferred to the impressions and then the cast is poured. It is mainly indicated in case of restricted mouth opening, limited access areas (posterior) and severe gagging patients, the closed tray impression technique are better choice.

C.Snap-fit (press fit) plastic impression coping: This technique does not require an open tray, but instead uses a closed tray. The press-fit impression coping is connected to the implant by pressing instead of screwing and the plastic impression copings are picked up in the impression.

\section{Advantages}

1. Helps to overcome the movement of impression coping inside the impression material

2. Time saving

3. Used in both the open and closed tray implant impression techniques

4. More comfortable for both the clinician and the patient

The snap-fit technique may be a reliable impression making technique but regarding accuracy of this technique none of the study is available for investigation.

\section{Abutment Level Impression}

If there is a requirement to replace old implant supported crown, abutment level impression is indicated just like crown and bridge cases. Abutmentlevelimpression with open tray technique is more accurate Employing conventional crown and bridge impression techniques for accurate implant abutment level impressions may be required when further modifications need to be applied to prefabricated or customized implant abutments. It has been reported that the accuracy of the implant-abutment level impression is higher when the pick-up technique is used as opposed to conventional crown and bridge impression technique; the fixture-level method was not superior to the abutment-level technique in terms of angular accuracy and most of the linear errors. The abutment-level method showed a better linear accuracy in the case of highly diverged posterior implants. Increasing the angle of implants' divergence from $40^{\circ}$ to $60^{\circ}$ might not usually lead to a significant increase in the errors, especially when using abutment-level impressions. Implant splinting technique is to stabilize the impression copings during the subsequent clinical and laboratory impression transfer procedures and to minimize 3-D spatial relationship changes. The shim splinting technique introduced in the present technique report offers an alternative to previously reported approaches such as the block/ splinting approach. Moreover, the shim splinting technique has several 
advantages such as a simpler laboratory fabrication process, less patient chair time, and the need for fewer implant components. The most commonly used transfer techniques for implant supported prostheses with multiple abutments are indirect, direct, and direct splinted. Some authors have noted that the impression made by the direct transfer technique for implants with splinting is more accurate than that of other techniques. Chemically activated acrylic resin is frequently used to fabricate intraoral splinting to join impression copings during the open-tray implant impression technique. However, some splinting methods can be used, each with advantages and disadvantages. The technique that uses dental floss as a framework for chemically activated acrylic resin is used thoroughly and demands longer clinical time for application. Other splinting forms are prefabricated bars and metal sticks, which use a smaller amount of acrylic resin. However, digital dentistry has introduced new methods in which conventional impression techniques are substituted with intra-oral scanners.

\section{Digital dental implant impressions [15-17]}

More recently, one of the major developments in implant prosthodontics has been the adoption of engineering principles in the form of computer-aided design and computer aided manufacturing (CAD/CAM) to construct implant prosthesis. This technology utilizes 3- D intraoral scanners which has revolutionizing the way we take impressions .The digital implant impression technique has proven its possibilities as an effective alternative for the analogue impression-taking technique

\section{The three main components required for the} CAD/CAM are the

1. The digital scanner to which transforms the geometry into the digital data which can be processed by the computer

2. Software that processes the data

3. A production technology that transforms the data set into the desired product

4. There are three different concepts in $\mathrm{CAD} / \mathrm{CAM}$ production in dentistry.

\section{Chair Side production}

All the components are available at the chair side and thus dental restoration fabrication takes place without a laboratory procedure. The intra oral digital scanner registers the clinical situation and offers the patient indirectly fabricated restoration in a single visit. Cerec system (Sirona) offers this facility. Variety of materials can be processed from glass-ceramic to high performance oxide ceramic, since Cerec system functions with water cooling.

\section{Laboratory production}

The first step is similar to the traditional FPD impression. The dentist sends the impression to the laboratory and the master cast is scanned to obtain the 3-dimensional data. The CAD process data will be sent to a special milling devices and that produces the real geometry in the dental laboratory.

\section{Centralized production}

In this, the prosthesis is fabricated in a milling centre. The satellite scanner in the laboratory is connected with a production centre via the internet. Data collected in the laboratory are sent to the production centre for the fabrication of prosthesis with a $\mathrm{CAD} / \mathrm{CAM}$ device. The benefit of this system is only small investment needed for the CAD system and high quality production obtained from the centre

\section{Benefits of the digital impression for implant rehabilitation}

1. Eliminates tray selection

2. Eliminates dispensing and setting of impression material

3. Disinfection and shipping of impression to the laboratory not required

4. Patient comfort and education

5. Virtual assessment for implant prosthetic space, depth of restorative interface, emergence profile configuration before proceeding with lab steps.

6. Digital scanning data base can be stored in computer hard drives which are not subjected to physical damage.

7. More efficient, more predictable

8. Allows additional re-scans without repeating entirely the impression technique and save chair time for patients.

9. Other application of $\mathrm{CAD} / \mathrm{CAM}$ is to produce implant abutments and frame work from metal or ceramic materials.

10. Digital impression allows for day-of-surgery impressions and indexing for creating custom abutments to place the final restoration earlier in the healing period after implant integration. ${ }^{18}$

\section{CONCLUSION}

A good impression is the key for success of the prosthetic treaments for proper transfer of the treatment plant tothe final result a good impression will be the key facror. For making a good impression through knowledge about the components, materials and treatment plant should be present. For a good impression selection of the impression technique also important for that particular clinical situation.

\section{REFERENCES}

1. Bohnenkamp, D. M., \& Garcia, L. T. (2007). Phonetics and tongue position to improve mandibular denture retention: a clinical report. The Journal of prosthetic dentistry, 98(5), 344-347.

2. Devaraju, K., Rao, S. J., Joseph, J. K., \& Kurapati, S. R. K. (2018). Comparison of biomechanical 
Yogesh Santoba Nagargoje et al., Saudi J Oral Dent Res, September, 2020; 5(9): 476-480

properties of different implant-abutment connections. Indian Journal of Dental Sciences, 10(3), 180.

3. Tabesh, M., Alikhasi, M., \& Siadat, H. (2018). A comparison of implant impression precision: Different materials and techniques. Journal of clinical and experimental dentistry, 10(2), e151.

4. Conrad, H. J., Pesun, I. J., DeLong, R., \& Hodges, J. S. (2007). Accuracy of two impression techniques with angulated implants. The Journal of prosthetic dentistry, 97(6), 349-356.

5. Nissan, J., \& Ghelfan, O. (2009). The press-fit implant impression coping technique. Journal of Prosthetic Dentistry, 101(6), 413-414.

6. Lahori, M., Mahesh, L., Nagrath, R., \& Singh, S. (2012). An Evaluation of the Accuracy of Multiple Implant Impression Techniques: An in Vitro Study. J Implant Adv Clin Dent, 4, 57-69.

7. Assif, D., Marshak, B., \& Schmidt, A. (1996). Accuracy of implant impression techniques. International Journal of Oral \& Maxillofacial Implants, 11(2).

8. Naconecy, M. M., Teixeira, E. R., Shinkai, R. S., Frasca, L. C. F., \& Cervieri, A. (2004). Evaluation of the accuracy of 3 transfers techniques for implant-supported prostheses with multiple abutments. International Journal of Oral \& Maxillofacial Implants, 19(2).

9. Kalpana, D., Smitha Sharan, D., Sreeharsha, T. V., Pradeep Chandra, K., Brunda, K., \& Nadira Jabeen, S. (2019). A review on dental implant impressions.

10. Block, M. S., Kent, J. N., \& Guerra, L. (1997). Implants in dentistry: essentials of endosseous implants for maxillofacial reconstruction. WB Saunders company.
11. Papaspyridakos, P., Chen, C. J., Gallucci, G. O., Doukoudakis, A., Weber, H. P., \& Chronopoulos, V. (2014). Accuracy of Implant Impressions for Partially and Completely Edentulous Patients: A Systematic Review. International Journal of Oral \& Maxillofacial Implants, 29(4).

12. Wee, A. G. (2000). Comparison of impression materials for direct multi-implant impressions. The Journal of prosthetic dentistry, 83(3), 323-331.

13. Barrett, M. G., de Rijk, W. G., \& Burgess, J. O. (1993). The accuracy of six impression techniques for osseointegrated implants. Journal of Prosthodontics, 2(2), 75-82.

14. Pathi, V., Joseph, J. K., \& Yadav, R. IMMEDIATE LOADING OF DENTAL IMPLANTS.

15. Kurtulmus-Yilmaz, S., Ozan, O., Ozcelik, T. B., \& Yagiz, A. (2014). Digital evaluation of the accuracy of impression techniques and materials in angulated implants. Journal of dentistry, 42(12), 1551-1559.

16. Papaspyridakos, P., Chen, C. J., Gallucci, G. O., Doukoudakis, A., Weber, H. P., \& Chronopoulos, V. (2014). Accuracy of Implant Impressions for Partially and Completely Edentulous Patients: A Systematic Review. International Journal of Oral \& Maxillofacial Implants, 29(4).

17. Kim, J. H., Kim, K. R., \& Kim, S. (2015). Critical appraisal of implant impression accuracies: a systematic review. The Journal of prosthetic dentistry, 114(2), 185-192.

18. Pjetursson, B. E., Thoma, D., Jung, R., Zwahlen, M., \& Zembic, A. (2012). A systematic review of the survival and complication rates of implant $\square$ supported fixed dental prostheses (FDP s) after a mean observation period of at least 5 years. Clinical oral implants research, 23, 22-38. 